\title{
List of Plants collected in Mimasaka and its vicinities.
}

(Continued from p. 26).

By

\section{T. Yubuki.}

\section{Moraceæ.}

Morus aibu, I. var. styloea, Bur. (ク ハ) Vicinity of Tsuyama. Broussonetia kasinoki. Siel. (カシゾ) Vicinity of Tsuyama. Humulus japonicus, S. et Z. (カナムグラ) Vicinity of Tsuyama. Fatona pilosa, Gand. var. subcordata. Rupr. (クハクサ) Mt. Yokono.

\section{Urticaceæ.}

Urtica divica, L. var. angustifulia, Led. (ホソバイラクサ) Vicinity of Tsuyama.

U. Thunbergiana, S. et Z. (イラクサ) Village of Tokuyama.

Nanocnide japonica, Bl. (カランサ) Vicinity of Tsuyama.

Laportea builbifera, Wedd. (ムカゴイラクサ) Mt. Yokono.

Achudenia japonica, Maxim. (ヤマミッ゙) Mt. Yokono.

Buhmerianivea, B]. ( $\nabla 7$ ) Vicinity of Tsuyama.

B. spicata, Thunb. (コアカン) Village of Okutsu.

B. japonica, Miq. $(\bullet フ ゙ マ \ni)$ Vicinity of Tsuyanı.

B. holusericea, Bl. (オニヤブマヨ) Vicinity of Tsuyama.

Elatostema unbellatum, Bl. (クチナハシャウゴ) Vicinity of T'suyama.

\section{Lcranthaceæ.}

Vircum album, L. (ヤドリキ) Vicinity of Tsuyama.

Loranthus Kæmpferi, Maxim. (マッグミ) Vicinity of T'suyama. 


\section{Santalacєæ.}

Thesium chinense, Turcz. (カナビキサウ) Vicinity of Tsuyama.

Buckleya quadriala, B. et H. (ツクバ子) Mt. Nagi.

\section{Aristolochiaceæ.}

Asarum Sieboldi, Miq. (ウスバサイシン) Mt. Riosangi.

A. caulescens, Miq. (

) Mt. Riosangi.

Aristolochia Kempferi, Willd. (オホパノウマノスズグサ) Vicinity of Tsuyama.

A. debilis, S. et Z. (ウマノスズクサ) Vicinity of Tsuyama.

\section{Polygonaceæ.}

Polygonum posumba, Ham. (ハナタデ) Vicinity of Tsuyama.

P. viscosum, Ham. var. vernicorum. Meisn. (チバリタデ) Vicinity of Tsuyama.

P. flaccidum, Roxb. (ヤナギタデ) Vicinity of Tsuyama.

P. virginianum, L. (ミッ゙ヒキ) Vicinity of 'Tsujama.

P. aviculare, L. (ニハャナギ) Vicinity of Tsuyama.

P. lipathifolium, Ait. (オホイヌタデ) Vicinity of Tsuyama.

P. alatum, Ham. (タニソバ) Mt. Hiru.

P. Thunbergii, S. et Z. (ミゾソバ) Vicinity of Tsuyama.

P. sagittatum, L. (アキノウナギヅル) Vicinity of Tsuyama.

P. cuspidatum, S. et Z. (イタドリ) Vicinity of Tsuyama.

P. posumba, Ham. var. Blumei, Meisn. (イヌタデ) Vicinity of Tsuyama.

P. orientale. I. var. pilosum, Meisn. (オホケタデ) Vicinity of Tsuyama.

P. senticosum, Miesn.?(ママコノシリヌグヒ) Vicinity of Tsuyama.

P. sieboldi, Meisn. (ウナギッ゙ル) Vicinity of Tsuyama.

P. sachalinense, Fr. Schm. (オホイタドリ) Mt. Nagi.

Rumex japonicus, Meisn. (ギシギシ) Vicinity of Tsuyama.

R. aquaticus, L. var. japonicus, Meisn. (マダイワウ) Vicinity of Tsuyama.

R. acetosa, L. (スカンポ) Vicinity of Tsuyama.

\section{Chenopodiaceæ.}

Chenopodium album, L. (アカザ) Vicinity of Tsuyama. 


\section{Amarantaceæ.}

Amarautus Blitum, L. (イヌビユ) Vicinity of T'Suyama.

Achyranthes bidentata, Bl. var. japonica, Miq. (イノシッ゙チ) Vicinity of Tsuyama.

\section{Phytolaccaceæ.}

Phytolacca acinosa, Roxb. var. esculenta, Miq. (ヤマゴバウ) Vicinity of Tsuyama.

\section{Portu'acaceæ.}

Portulaca oleracea, L. (スベリヒエ) Vicinity of Tsuyama.

\section{Caryophyllaceæ.}

Dianthus superbus, L. (カーラナデショ) Vicinity of Tsuyama.

Cucubalus baccifer, L. var. japonicum. Miq. (ナンバンハコべ) Vicinity of Tsuyama.

Lychnis Miqueliana, Ruhr. (フシグロセンコウ) Riosan Mt. Nagi.

Cerastium vulgatum, L. var. glandulosum, Koch. (ミミナグサ) Vicinity of 'Tsuyama.

Melandryum firmum, Rohrb. (サッマニンジン) Mt. Nagi.

Stellaria media, Vill. (ハコべ) Vicinity of Tsuyama.

S. aquatica, Scop. (クシハコベ) Vicinity of T'Tuyama.

S. nemorum, L. var. Bungeana Maxim. (ミヤマハコべ) Mt. Yokono.

S. uliginosa, L. (ノミノフスマ) Vicinity of T'suyama.

S. monosperma, Ham. var. japonica Maxim. (オホヤマハコべ) Mt. Yokono.

Mwehringia lateriflora, Fengl. (オホャマフスマ) Mt. Yokono.

Sagina Linnæi Presl. var. maxima, Maxim. (ツメクサ) Vicinity of Tsuyama.

\section{Nymphæaceæ.}

Brasenia purpurea, Casp. (ジンサイ) Vicinity of Tsuyama.

Nuphar japonicum, DC. (カハホ子) Vicinity of Tsuyama.

Nymphwa tetragona, Georg. var. angusta Casp. (ヒツジグサ) Vicinity of Tsuyama.

Nelumbo nucifera, Grorn. (ハス) Vicinity of Tsuyama. 


\section{Aizoaceæ.}

Mollugo stricta, L. (サグロサウ) Vicinity of Tsuyama.

\section{Magnoliaceæ.}

Magnolia liypoleuca, S. et Z. (ホホノキ) Mt. Nagi. M. Kobus, DC. (コブシ) Mt. Nagi.

Schizandra nigra, Maxim. (マッブサ) Mt. Nagi.

Kadsura japonica, Dun. (サチカヅラ) Vicinity of Tsuyama.

Illicium Anisatum, L. (シキミ) Vicinity of Tsuyama.

\section{Trochodendraceæ.}

Euptelea polyandra, S. et Z. (フサザクラ) Mt. Nagi.

Cercidiphyllum japonicum, S. et Z. (カッラ) Mt. Nagi.

Trochodendron aralioides, S. et Z. (ヤマグルマ) Mt. Nagi.

\section{Ranunculaceæ.}

Clematis recta L. var. paniculata, Thunb. (ヒンニンサウ) Vicinity of Tsuyama.

C. apiifolia. DC. (ポタンヅル) Vicinity of Tsuyama.

C. florida, Thunb. (カザグルマ) Vicinity of Tsuyama.

C. japonica, Thunb. (ハンシャウジル) Vicinity of T'suyama.

C. heracleifolia, DC. var. stans. (クサボタン) Mt. Hiru.

Thalictru maquilegifolium, L. (カラマッサシ) Vicinity of Tsuyama.

T. actæfolium, S. et Z. (シギンカラマッ) Vicinity of Tsuyama.

T. minus, L. var. elatum Lecoy. (アキカラマッサウ) Vicinity of Tsuyama. Anemone cernua, Thunb. (オキナクサ) Vicinity of Tsuyama.

A. japonica, S. et Z. (シウメイギク) Vicinity of Tsuyama.

A. nikoensis, Maxim. (イチリンサウ) Mt. Izumi.

A. flaccida, Fr. Schm. (ニリンサウ) Mt. Izumi.

Ranunculus acer, L. var. japonica Maxim. (キンボウゲ) Vicinity of Tsuyama.

R. pensylvanicus, L. F. (キッチノボタン) Vicinity of Tsuyama.

R. sceleratus, L. (タガラシ) Vicinity of 'I'suyama. 
R. aquatilis, I. var. flaccidus Forma Drouetii, Hiern (パイクワモ) Village of Tokuyama.

Coptis trifolia, Salisb. (ミツバワウレン) Mt. Hiru.

C. anemonæfolia, S. et Z. (キクバワウレン) Mt. Hiru.

Isopyrum dicarpon, Miq. (サバノ タ) Mt. Nagi.

I. adoxoides, DC. (ヒメウッ゙) Village of Tsuyama.

Aconitum Fischeri, Reich. (ヤマトリカブト) Mt. Hiru.

Cimicifuga foetida, L. var simplex, Huth. (サラシナジャウア) Mt. Nagi.

\section{Lardizabalacєæ.}

Akebia quinata, Decne. (アケビ) Vicinity of Tsuyama.

A. lobata, Decne. (ミッパアケビ) Vicinity of Tsuyama.

Stauntonia hexaphylla, Decne. (ムぶ) Vicinity of Tsuyama.

\section{Berberidaceæ.}

Berberis Thunbergii, DC. ( $キ キ)$ Mt. Nagi.

Epimedium macranthum, Morr. et Dene. (イカリサウ) Mt. Riosangi.

\section{Menispermaceæ.}

Cocculus Thunbergii, DC. (ア ッッッ゙ラフデ) Village of Kogawa. Menispermum diversifolium. Prantl. (カウモりカッ゙ラ) Village of Kogawa.

\section{Lauraceæ.}

Lindera precox, Bl. (アブラチヤン) Mt. Nagi.

L. sericea, Bl. (クロモジ). Mt. Nagi.

L. membranacea, Maxim. (オホバクロモジ) Mt. Nagi.

L. obtusiloba, Bl. (タンカウバイ) Mt. Nagi.

L. umbellata, Thunb. (カナクギノキ) Mt. Nagi.

Cinnamomum pedunculatum, Nees. ( ブニクケイ) Village of Tsuyama. Machilus Thunbergii, S. et Z. (タブノキ) Village of Tsuyama.

\section{Papaveraceæ.}

Hylomecon japonica, P. (ヤマブキサウ) Mt. Nagi.

Chelidonium majus, L. (クサノワウ) Vicinity of Tsuyama. 
IVol. XVI,

Macleya corlata, R. B. (タタニクサ) Vicinity of Tsuyama.

Corydalis incisa, Pers.(ムラサキケマン) Vicinity of T'suyama.

C. pallida, Pers. (ミャマキタマン) Vicinity of Tsuyama.

- - var. platycarpa, Maxim. (キケマン) Vicinity of Tsuyama.

\section{Cruciferæ.}

Alliaria Wasabi, Prantl. (ワサビ) Mt. Nagi.

Nasturtium montanum, Wall. (イヌガラシ) Vicinity of Tsuyama.

N. palustre, DC. (タゴバウ) Vicinity of Tsuyama.

Cardamine hirsuta, L. var. sylvatica, Link. (タチツケパナ) Vicinity of Tsuyama.

C. impatiens, I. (ジャニンジン) Mt. Nagi.

Dentaria macrophylla, DC. (コンロンサウ) Mt. Nagi.

Capsella Bursa-pastoris, Muench. (ナッ゙ナ) Vicinity of Tsuyama.

Draba nemorosa, L. var. hebecarpa, Ledeb. (イヌナッ゙ナ) Vicinity of Tsuyama.

Arabis sagittata, DC. (ヤマハタザホ) Mt. Riusangi.

A. flagellosa, Miq. (スズシロサウ) Mt. Riosangi.

\section{Droseraceæ.}

Drosera rotundifolia, I. (マウセンゴケ) Vicinity of Tsuyama.

D. lunata, Buch. (イジモチサウ) Mt. Nagi. 